\title{
Língua inglesa: tempo de colheita
}

\author{
MUNIRA H. MUTRAN
}

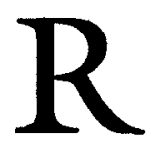

ua Maria Antônia, fim da década de cinquienta. $O$ vestibular para Inglês incluía, além dos exames escritos, uma prova oral para todas as disciplinas. A de Latim, por exemplo. Reunidos em uma sala, os candidatos dispunham de algum tempo para ler e tentar traduzir o texto sorteado; em seguida, eram chamados. Surpresa, percebi que aquele trecho de Cícero que tinha em măos havia sido esmiuçado e trabalhado exaustivamente nas aulas do professor Pina no Clássico do Colégio Roosevelt da Gabriel dos Santos; com segurança fui respondendo às perguntas de D. Aída Costa e traduzindo. Já me sentia na USP.

O curso de Inglês, com apenas três professores - Kenneth Buthlay, Kera Stevens e Joăo Fonseca - , apresentava forte tendência para a literatura, desde o início. Os alunos já entravam na universidade com bom conhecimento de língua, reforçado depois pela leitura e discussáo de textos literários. Além disso, a conversação ficava por conta dos coquetéis de sexta-feira na Cultura Inglesa, organizados para que os alunos pudessem conhecer native speakers (geralmente sócios do Clube Inglês ou pessoas trabalhando em firmas inglesas no Brasil). Naquele tempo era tudo em pequena escala: o corpo docente, o número de alunos, a biblioteca composta de doações, a salinha do $4^{\circ}$ andar, onde a máquina de escrever, uma Royal, modelo Quiet de Luxe, no 2.380.076, e uma estante de afo modelo Securit medindo 2,40 m de altura, 2,76 de largura, dividida em tres sefóes adquiridas em 1952, eram peças importantes. Contrastando com tais recursos, as exigências de qualidade eram amplas. No Anuário de 1937-1938 um professor de História comenta que "é indispensável que se exija no futuro que $o$ aluno que pretenda especializar-se na história da civilizaçáo americana conheça todas as línguas do continente" ; acrescenta, com certa justeza, que "o francês e o espanhol não oferecem obstáculos ao aluno brasileiro, mas em geral são poucos os que têm conhecimentos suficientes de Inglês" (1).

O curso de Letras Anglo-Germânicas começou a funcionar na FFCL em 1940 com sete alunos inscritos; em 1941 o número dobrou para 14, em 1942 subiu para 55, mas caiu para 28, 9 e 15 nos anos 
seguintes. Apresentava os mesmos objetivos apontados pelos demais cursos iniciados em 1934:

- preparar trabalhadores intelectuais para o exercício de altas atividades culturais de ordem desinteressada ou técnica;

- preparar candidatos ao magistério do ensino secundário, normal e superior;

- realizar pesquisas nos vários domínios da cultura que constituem o objeto de seu ensino.

O currículo de Anglo-Germânicas incluía Língua Latina, Filologia e Língua Portuguesa, Língua Inglesa e Literatura Anglo-Americana, Língua e Literatura Alemá, e História Medieval. A última disciplina, oferecida no $1^{\circ}$ ano pelo professor Pedro Moacyr Campos, punha em prática a interdisciplinaridade, táo valorizada atualmente, ensinando uma abordagem científica no trabalho de pesquisa sobre a Idade Média na Inglaterra e na Alemanha.

Da fase inicial do curso devemos sempre nos reportar aos Amuários, os quais nos informam que para a Cadeira de Ingles foi convidado o professor Douglas Redshaw, então diretor da Sociedade Brasileira de Cultura Inglesa, que ocupou a cátedra de 1940 até 1942. No período de 1942 a 1947 o professor John Kenneth Swann, também da Cultura Inglesa, o substituiu. Durante sua gestáo foi nomeado como $1^{\circ}$ assistente Hygino Aliandro. Em 1948 foi indicado pelo Conselho Britânico, o professor Geoffrey Wile; ao fim de seu contrato, o assistente regeu interinamente a Cadeira até a chegada do professor John Francis Tuohy em 1950, que por sua vez foi substituído pelo professor Kennneth Buthlay em 1955.

Com a abertura das classes noturnas aumentaram as atividades do Curso; foram contratados os professores Joáo Fonseca, que se dedicou à docência e à composiçăo de livros para o ensino de Inglês no $1^{\circ}$ grau, e Onédia Célia de Oliveira Barbosa, que iria desenvolver e consolidar o estudo de Literatura Comparada com sua pesquisa sobre Byron no Brasil, e a de seus mestrandos e doutorandos, sobre a recepçáo de autores de língua inglesa, como Whitman e Wilde.

Com a partida do professor Kenneth Buthlay em 1964 encerra-se uma fase: o vínculo estreito com o Conselho Britânico, que havia desempenhado papel muito significativo nas décadas de quarenta e cinqüenta, dá lugar ao intercâmbio de idéias e experiências entre os professores visitantes e os docentes brasileiros, em convênios informais ou formais. Aos poucós o curso estabelece relaçôes culturais com os Esta- 
dos Unidos, principalmente nas décadas de sessenta e setenta, através da Comissão Fulbright e, mais tarde, com a Irlanda e o Canadá.

Nas décadas de estruturação e desenvolvimento em nível de pósgraduaçáo, alguns docentes destacaram-se ao iniciar linhas de pesquisa e ao orientar dissertaçóes e teses, tanto de jovens docentes do próprio curso quanto de pesquisadores de outras instituiçóes estaduais e federais.

$\mathrm{Na}$ área de Língua Inglesa, já em 1965, os programas de graduação recebem uma abordagem lingüística pela professora Martha Steinberg. As teorias de Pike e Nida discutidas em seus cursos de pós-graduaçáo serviram de embasamento para novos caminhos de pesquisa que na verdade podem ser resumidas em um só: a análise contrastiva entre o português e o inglês. Tendo percorrido esse universo lingüístico verbal passou-se à pesquisa do não-verbal, resultando teses e dissertaçóes importantes.

Da linha de análise contrastiva surgiu bom material para os cursos de Traduçáo, que funcionaram como modalidade da graduaçá, especialização e, a partir de 1993, como de pós-graduação lato-sensu. Dentro dessa área existem vários projetos de Teoria da Traduçáo Literária, já concluídos ou em andamento, com traduçáo de autores americanos, canadenses e irlandeses, $\mathrm{e}$ ainda com a versão da poesia brasileira para 0 inglês.

Outra linha da área de Língua Inglesa, a de Convencionalidade $e$ Idiomaticidade, que já formou um mestre e possui oito pós-graduandos com diferentes interesses de pesquisa, ocupa-se atualmente do projeto de um dicionário bilingüe de coligaçôes verbais.

Recentemente os programas de Língua Inglesa foram enriquecidos com a contratação de docentes com formaçáo em outras instituiçóes superiores, cuja abordagem e contribuição deram novos contornos ao curso nas linhas de Lingüística Aplicada e Análise do Discurso com relaçáo ao processo de ensino/aprendizagem da língua estrangeira em seus diversos aspectos, como o bilingüismo e o ensino da leitura.

$\mathrm{Na}$ área de Literaturas de Língua Inglesa o professor Paulo Vizioli, responsável pelo curso desde 1964 até 1986, ministrou cursos e orientou cinco dissertaçóes e sete teses em diferentes linhas de pesquisa. Como crítico, tradutor e ensaísta divulgou a poesia, o teatro e a ficçáo de escritores ingleses e norte-americanos.

Na mesma área, a professora Kera Stevens, com seu interesse por poetas românticos ingleses - em especial Byron - e obra de Shakes- 
peare, orientou seis dissertaçóes e quatro teses, influenciando o ensino da literatura não só na USP mas também no país.

A linha de pesquisa sobre Literatura do Sul dos Estados Unidos teve produção acadêmica bastante significativa. A professora Yedda Tavares ministrou vários cursos e orientou dissertaçōes sobre Eugene O'Neill, Tennessee Williams, Faulkner, Eudora Welty, Katherine Anne Porter e Jack Kerouac, e um doutorado sobre Tom Stoppard.

A Presenfa da Literatura Irlandesa, linha iniciada em 1980, já formou três mestres e um doutor. Dedica-se atualmente a um projeto integrado envolvendo o docente responsável, cinco doutorandos e quatro mestrandos, professores de diferentes universidades brasileiras. Tal projeto visa a estudar o teatro irlandês e a cena cultural na Irlanda no período de 1890-1930 através de documentos do eu, como cartas e autobiografias. Esse núcleo de Literatura Irlandesa fundou a ABEI Associafão Brasileira de Estudos Irlandeses - que já publicou sete números de seu $A B E I$ Newsletter.

As linhas de pesquisa literária mais recentes como $A$ fiçẫo norteamericana no século $X X$, Estudo das teorias criticas em língua inglesa em relafẵo ao universo intelectual brasileiro, Poesia norte-americana dos séculos $X I X$ e XX, O teatro inglés do pós-guerra, Tendéncias do romance inglés do século $X V I I I$, têm oferecido diversos cursos e contam com grande número de orientandos em diferentes etapas da pesquisa.

Como se vê, as perspectivas são promissoras. Houve ao longo dos anos, aumento do número de docentes (15) e alunos (373 na graduaçáo e 60 na pós-graduação); 35 dissertações e 25 teses defendidas desde 1950; melhora espantosa na infra-estrutura; e grande diversificação nos cursos oferecidos. Os extracurriculares, por exemplo, ou os G.T. (grupos de trabalho) têm propiciado maior aproximaçăo das disciplinas que compóem o Departamento de Letras Modernas. Essa abertura para as outras disciplinas é característica (ou retorno?) de uma nova visão do curso, náo como entidade cultural estanque, mas como parte de um todo.

Ao completar 54 anos o Curso de Inglês demonstra bastante vigor. É o tempo da colheita. Como na parábola, algumas sementes podem ter caído nas rochas, ou nos espinhos, ou à beira da estrada; mas as que caíram em solo fértil frutificaram. É significativo que nosso mais recente projeto seja uma publicação que deverá reunir contribuiçóes de alunos e docentes da pós-graduação. Seu título, Crop foi inspirado nos seguintes versos do poema Gathering leaves, de Robert Frost: 
But a crop is a crop

And who's to say

When the harvest shall stop?

\section{Nota}

1 Esses e todos os outros dados referentes ao histórico do Curso de Inglês encontram-se nos Anudrios da Faculdade de Filosofia, Ciências e Letras consulrados graças à colaboraçáo da professora Miriam Moreira Leite, coordenadora do Projeto Mamória da Faculdade de Filosofia.

Munira H. Mutran é professora do Departamento de Letras Modernas da Faculdade de Filosofia, Letras e Ciências Humanas da USP. 